\title{
Surface controlled biomimetic coating of polycaprolactone nanofiber meshes to be used as bone extracellular matrix analogues
}

\author{
J. V. ARAUJO ${ }^{1,2}$, A. MARTINS ${ }^{1,2}$, I. B. LEONOR ${ }^{1,2}$, E. D. PINHO ${ }^{1,2}$, \\ R. L. REIS ${ }^{1,2}$ and N. M. NEVES ${ }^{1,2, *}$ \\ ${ }^{1}$ 3B's Research Group - Biomaterials, Biodegradables and Biomimetics, Department of Polymer \\ Engineering, University of Minho, Campus de Gualtar, 4710-057 Braga, Portugal \\ ${ }^{2}$ IBB - Institute for Biotechnology and Bioengineering, PT Government Associated Laboratory, \\ Braga, Portugal
}

Received 3 April 2007; accepted 9 November 2007

\begin{abstract}
The aim of this work was to develop novel electrospun nanofiber meshes coated with a biomimetic calcium phosphate (BCP) layer that mimics the extracellular microenvironment found in the human bone structure. Poly ( $\varepsilon$-caprolactone) (PCL) was selected because of its well-known medical applications, its biodegradability, biocompatibility and its susceptibility to partial hydrolysis by a straightforward alkaline treatment. The deposition of a calcium phosphate layer, similar to the inorganic phase of bone, on PCL nanofiber meshes was achieved by means of a surface modification. This initial surface modification was followed by treatment with solutions containing calcium and phosphate ions. The process was finished by a posterior immersion in a simulated body fluid (SBF) with nearly $1.5 \times$ the inorganic concentration of the human blood plasma ions. After some optimization work, the best conditions were chosen to perform the biological assays. The influence of the bone-like BCP layer on the viability and adhesion, as well as on the proliferation of human osteoblast-like cells, was assessed. It was shown that PCL nanofiber meshes coated with a BCP layer support and enhance the proliferation of osteoblasts for long culture periods. The attractive properties of the coated structures produced in the present work demonstrated that those materials have potential to be used for applications in bone tissue engineering. This is the first time that nanofiber meshes could be coated with a biomimetic bone-like calcium phosphate layer produced in a way that the original mesh architecture can be fully maintained.
\end{abstract}

Key words: Biomimetic calcium phosphate; polycaprolactone; electrospinning; nanofibers; osteoblastlike cells; surface modification; biomimetic coating.

\footnotetext{
*To whom correspondence should be addressed. E-mail: nuno@dep.uminho.pt
} 


\section{INTRODUCTION}

Poly( $\varepsilon$-caprolactone) (PCL) is a US Food and Drug Administration (FDA)-approved polymer that is subjected to hydrolytic degradation due to the susceptibility of its aliphatic ester linkage to hydrolysis $[1,2]$. Due to the good mechanical properties of this polymer and to its biocompatibility and biodegradability, scaffolds of PCL have been used in different branches of tissue engineering, mainly in the applications where flexible materials are required, i.e., bone substitution and regeneration $[3,4]$. It is well known that, for bone-related applications, the ideal biodegradable polymer scaffolds should have adequate osteointegration, as well as be characterized by osteoconduction and osteoinduction. These properties could facilitate the integration with native bone and eventually promote new bone formation [5]. In this sense, the hybridization of PCL with bioactive ceramics, such as hydroxyapatite (HA), to obtain scaffolds with the above-mentioned characteristics has been shown to lead to very promising properties [2, 3]. Most of these hybrid scaffolds are prepared by the dispersion of the mineral phase into the polymer matrix. However, those techniques are limited by the poor adhesion of the cells to the composite surfaces. In this sense, the coating of polymers with a calcium phosphate layer rendering the obtained structures with adequate bone-bonding or osteoconductive properties has been evaluated [6-9]. Moreover, the presence of the calcium phosphates may tailor the degradation and resorption of the polymer matrix $[2,6,10]$. Additional benefits could involve the improvement in cell adhesion, proliferation and eventually the osteogenic differentiation of progenitor cells [6, 8, 9, 11-14]. Among the techniques used to achieve this goal [15-18], biomimetic coatings are very promising candidates. The coated polymers are characterized by a homogenous distribution of a biomimetic calcium phosphate (BCP) phase at the polymer surface. Based in this concept, Kokubo et al. [19] developed a methodology to coat different inorganic and organic materials with bioactive layers. The main aim of this biomimetic process is to mimic the biomineralization process at physiological conditions, leading to the formation of a BCP layer on the surface of the substrate. This approach has the advantage to coat porous three-dimensional structures $[15,20]$. The substrates coated with the calcium phosphate layer by the biomimetic process have great potential for bone-repairing applications, since they can exhibit high bioactivity and biocompatibility, as well as mechanical properties analogous to the ones of natural cancelous bone [21, 22]. The original biomimetic method for coating different substrates with BCP includes two steps. Initially, the substrates are covered with a $\mathrm{CaO}-\mathrm{SiO}_{2}$-based glass particles and immersed in a simulated body fluid (SBF) [23], a solution with ion concentrations nearly equal to those of human plasma, at $36.5^{\circ} \mathrm{C}$ (first treatment designated as the nucleation period). Subsequently, the substrates are immersed in another solution, e.g., $1.5 \times \mathrm{SBF}$, with ion concentrations 1.5 times those of the $\mathrm{SBF}$ at $36.5^{\circ} \mathrm{C}$ (second treatment designated as the growth period). The thickness of the resulting BCP layer increases with the immersion time in the second treatment. The rate of growth of the BCP layer increases with the ion concentration of the second solution [21]. Such methodology, 
however, requires a long period to induce the nucleation of the calcium phosphate. Furthermore, in biomedical applications it is required that the coatings have strong adhesion of the inorganic layer to the substrate. In order to decrease the induction period, as well as to increase the adhesion between the BCP layer and the polymer surfaces, several chemical modifications can be achieved. Those modifications aim at providing the polymer surfaces with chemical groups that can induce the calcium phosphate nucleation by chemical interactions with the ions present in SBF. Different functional groups, including $-\mathrm{PO}_{4} \mathrm{H}_{2},-\mathrm{COOH}, \mathrm{Si}-\mathrm{OH}$ and $\mathrm{Ti}-\mathrm{OH}$, have been shown to be effective for the calcium phosphate nucleation [24-29]. Therefore, the period required for inducing the nucleation is a crucial factor in the calciumphosphate-forming ability of any material immersed in SBF. Parameters involved in this type of modification include chemical nature [25], number [24] and arrangement [27] of the functional groups at the surface. Oyane et al. [30] have shown that BCP coating was formed at the surface of modified PCL membranes and porous scaffolds in SBF. Those structures were previously treated with aqueous sodium hydroxide $(\mathrm{NaOH})$ solution and then dipped alternately in calcium and phosphate ion solutions. Although this methodology has been proven efficient to coat materials with 2D and 3D macrostructures, to our knowledge it is not the development of studies concerning its application to structures with sub-micrometer characteristic dimensions, such as meshes produced by electrospinning.

Electrospinning has been proposed extensively as an efficient technique for the production of nanofibers of both synthetic and natural polymers [31-33]. Electrospun fibers present remarkable properties, namely an enhanced surface-areato-volume ratio due to the sub-micrometer range of the diameter of the fibers. These structures have also high interconnectivity and porosity in the micrometer range [34]. These properties and the fact that they can be easily manipulated and shaped to fill anatomical defects, suggested its use in tissue/organ repair and regeneration as biocompatible and biodegradable medical implant devices [35]. Another characteristic of electrospun nanofibers increasing its attractiveness for those applications is their considerable similarity with the extracellular matrices of tissues. It is believed that the meshes may consist in a more favorable microenvironment for the cells to regenerate tissues [35-38]. Up to now, only few studies have been undertaken to modify the electrospun polymer nanofibers in order to induce the formation of BCP layers. A recent work describes the behavior in SBF of electrospun nanofiber meshes of poly(L-lactic acid) (PLLA), another wellknown polyester, after surface modification using alkaline solutions [39]. Despite the good results obtained, the surface-modified samples took a long period to promote the nucleation of the calcium phosphate, at least 2 weeks. In the present work, surface modification of electrospun PCL nanofiber meshes was achieved using an aqueous $\mathrm{NaOH}$ solution. Afterwards, these surface-modified samples were immersed alternately into solutions containing calcium ions and phosphate ions to promote the precipitation of calcium-phosphate nuclei for the $\mathrm{BCP}$ to grow. In order to induce the growth of the $\mathrm{BCP}$ layer, surface-modified specimens, as well as those 
subjected to the treatment with solutions containing calcium and phosphate ions, were immersed in $1.5 \times \mathrm{SBF}$ for several days. The conditions that produced $\mathrm{BCP}$ coatings were chosen to perform the biological assays. It was evaluated the cell attachment and proliferation of osteoblast-like cells seeded in the nanofiber meshes coated with BCP layers.

\section{MATERIALS AND METHODS}

\section{Preparation of electrospun nanofiber meshes}

PCL $\left(M_{\mathrm{w}}=80 \times 10^{3}\right.$, Solvay Interox, UK) was dissolved in chloroform (Aldrich, Germany)/dimethylformamide (DMF; Aldrich, Germany) (70:30) at a concentration of $17 \%(\mathrm{w} / \mathrm{v})$. The obtained polymer solution was placed into a 5 -ml syringe, with a metallic needle having an internal diameter of $0.8 \mathrm{~mm}$ attached to it. The syringe was connected to a syringe pump (KDS100, KD Scientific, USA) to control the flow rate. A positive electrode was put in contact with the needle. Flat aluminum sheet covering the ground plate was used as the collector. A high voltage power supply was employed to generate the electrostatic field $(0-25 \mathrm{kV})$. The capillary tip-to-collector distance and the flow rate were $15 \mathrm{~cm}$ and $1 \mathrm{ml} / \mathrm{h}$, respectively. The applied voltage was of $9 \mathrm{kV}$. From this procedure it was possible to obtain fibers with diameters ranging from $250 \mathrm{~nm}$ to $2.5 \mu \mathrm{m}$. The conditions for the electrospinning were optimized to obtain a continuous process and a reproducible morphology of the meshes.

\section{$\mathrm{NaOH}$ treatment}

As-spun PCL nanofiber meshes were cut into a square shape $(10 \mathrm{~mm} \times 10 \mathrm{~mm})$. The specimens were immersed into a $0.5 \mathrm{M} \mathrm{NaOH}$ (Sigma, Germany) solution at $37^{\circ} \mathrm{C}$ and stirred at $70 \mathrm{rpm}$ for $12 \mathrm{~h}$. After removal from the $\mathrm{NaOH}$ solution, the specimens were washed five times with ultra-pure water and dried at $37^{\circ} \mathrm{C}$ for at least $5 \mathrm{~h}$.

\section{Calcium ion and phosphate ion treatments (CaP treatment)}

The NaOH-treated specimens were dipped in $0.1 \mathrm{M} \mathrm{CaCl}_{2}$ (Merck, Germany) (10 samples for each $50 \mathrm{ml}$ of the solution) at $37^{\circ} \mathrm{C}$ with agitation at $70 \mathrm{rpm}$ for 1 day. After removed from the calcium solution, the specimens were rapidly dipped in $10 \mathrm{ml}$ of ultra-pure water, immediately dipped in $10 \mathrm{ml}$ of $0.1 \mathrm{M} \mathrm{K}_{2} \mathrm{HPO}_{4} \cdot 3 \mathrm{H}_{2} \mathrm{O}$ (Merck, Germany) for $15 \mathrm{~min}$ and immersed again in $10 \mathrm{ml}$ of ultra-pure water for a few seconds.

\section{Immersion in simulated body fluid $(S B F)$}

The $\mathrm{NaOH}$-treated specimens and those subjected to the CaP treatment were dipped in $10 \mathrm{ml}$ of $1.5 \times \mathrm{SBF}$ [23] for different time periods. The ion concentration 
(in $\mathrm{mM}: \mathrm{Na}^{+} 243, \mathrm{~K}^{+} 7.5, \mathrm{Ca}^{2+} 3.8, \mathrm{Mg}^{2+} 2.6, \mathrm{Cl}^{-} 223, \mathrm{HCO}_{3}^{-} 6.3, \mathrm{HPO}_{4}^{2-}$ $1.5, \mathrm{SO}_{4}^{2-} 0.8$ ) of the $1.5 \times \mathrm{SBF}$ solution was approx. 1.5-times higher than in human blood plasma. $1.5 \times \mathrm{SBF}$ was prepared by dissolving $\mathrm{NaCl}$ (Panreac, Spain), $\mathrm{NaHCO}_{3}$ (Merck, Germany), $\mathrm{KCl}$ (Panreac, Spain), $\mathrm{K}_{2} \mathrm{HPO}_{4} \cdot 3 \mathrm{H}_{2} \mathrm{O}$ (Merck, Germany), $\mathrm{MgCl}_{2} \cdot 6 \mathrm{H}_{2} \mathrm{O}$ (Aldrich, Germany), $\mathrm{CaCl}_{2}$ (Merck, Germany) and $\mathrm{Na}_{2} \mathrm{SO}_{4}$ (Panreac, Spain) in ultra-pure water. The solution was buffered at $\mathrm{pH} 7.4$ with tris(hydroxymethyl)amino-methane (Aldrich, Germany) and $1 \mathrm{M} \mathrm{HCl}$ (Panreac, Spain) at $37^{\circ} \mathrm{C}$.

\section{Surface characterization}

The morphology of the nanofiber meshes, cut into square shapes $(10 \mathrm{~mm} \times 10 \mathrm{~mm})$, was characterized by Scanning Electron Microscopy (SEM) using a Leica Cambridge S360 microscope equipped with an energy dispersive spectrometer (EDS; link-eXL-II). Before SEM analysis, the specimens were sputter coated with gold or with carbon (for EDS observations). Infrared spectra were obtained with a Fourier transform infrared attenuated total reflection (FT-IR-ATR) spectrometer (IRPrestige-21, Shimadzu, Japan). Static contact angles of the nanofiber meshes, before and after $\mathrm{NaOH}$ treatment, were measured at room temperature with a contact-angle measuring system (OCA 15plus, DataPhysics Instruments, Germany). The used liquids (water, HPLC grade, $3 \mu \mathrm{l}$ ) were added by a motor driven syringe in different regions of each sample. A X-ray photoelectron spectrometer (XPS; VG Escalab 250 iXL ESCA), equipped with monochromatic $\mathrm{Al}-\mathrm{K}_{\alpha}$ radiation ( $h v=1486.92)$, was used to determine the surface composition of the specimens. Thin-film X-ray diffraction (TF-XRD) patterns were recorded on a Philips X'Pert MPD (Philips, The Netherlands) diffractometer using $\mathrm{CuK}_{\alpha}$ radiation.

\section{Cells}

Before being used in the biological studies, the samples were prepared as described in the CaP-treatment, placed in $1.5 \times \mathrm{SBF}$ for 4 days, washed with distilled water, dried and sterilized with ethylene oxide, which were the best conditions to perform the biological assays.

\section{Direct cell contact experiments}

Human primary osteogenic sarcoma cells (Saos-2; European Collection of Cell Cultures, UK) were cultured in Dulbecco's Modified Eagle's Medium (DMEM; Sigma-Aldrich, Germany) supplemented with $10 \%$ heat-inactivated fetal bovine serum (FBS; Biochrom, Germany) and 1\% antibiotic-antimycotic solution (Gibco, UK). The cells were maintained in a humidified atmosphere with $5 \% \mathrm{CO}_{2}$ at $37^{\circ} \mathrm{C}$, with medium changes every 2-3 days.

Direct contact assays were performed using both untreated PCL nanofiber meshes and PCL nanofiber meshes coated with a BCP layer. Tissue-culture polystyrene 
(TCPS) surfaces were used as control. Saos- 2 cells were seeded on the samples at a density of $1 \times 10^{5}$ cells $/ \mathrm{cm}^{2}$ (apparent surface area). The cells were cultured in 24-well cell-culture plates $\left(\operatorname{Costar}^{\circledR}\right.$; Corning, NY) for 1, 3, 7 and 14 days.

\section{Morphological characterization of cultured cells}

Adhesion, spreading and morphology of osteoblast-like cells seeded on coated PCL nanofiber meshes and controls were assessed by SEM morphology analysis. At the designated time points, the cells-nanofiber mesh constructs were first washed with phosphate-buffered saline (PBS; Sigma, USA) and then fixed with 2.5\% glutaraldehyde (Sigma, USA) solution in PBS for $1 \mathrm{~h}$ at $4^{\circ} \mathrm{C}$. The samples were further submitted to a dehydration process through a graded series of ethanol 25 , $30,50,70,80,90$ and $100 \%$ for 30 min each, and air-dried before mounting on aluminum stumps.

\section{Cell viability and proliferation assays}

The CellTiter $96^{\circledR} \mathrm{AQ}_{\text {ueous }}$ One Solution Cell Proliferation Assay (Promega, USA) is a colorimetric method for determining the number of viable cells in proliferation. This assay is based on the bioreduction of a tetrazolium compound, 3-(4,5-dimethylthiazol-2-yl)-5-(3-carboxymethoxyphenyl)-2-(4-sulfofenyl)-2H-tetrazolium (MTS), by the cells into a brown formazan product that is soluble in tissue culture medium. This conversion is presumably accomplished by NADPH or NADH produced by dehydrogenase enzymes in metabolically active cells. Briefly, culture medium was pipetted out from the 24-well tissue-culture plate and $500 \mu \mathrm{l}$ of fresh culture medium (without Phenol Red and FBS) was added to every well. CellTiter $96^{\circledR} \mathrm{AQ}_{\text {ueous }}$ One Solution reagent $(100 \mu \mathrm{l})$ was then added to every well. After culturing for $3 \mathrm{~h}$ in the incubator, $100 \mu \mathrm{l} / \mathrm{well}$ of the colored culture medium from each sample was transferred to a 96-well plate. The quantity of formazan product, as measured by the amount of $490 \mathrm{~nm}$ absorbance in a microplate reader (Synergie HT, Bio-Tek, USA), is directly proportional to the number of living cells in culture.

Cell proliferation was quantified using the Quant-iT ${ }^{\mathrm{TM}}$ Picogreen ${ }^{\circledR}$ dsDNA Quantitation assay (Molecular Probes, Leiden, The Netherlands). According to the manufacturer, the Quant-iT ${ }^{\mathrm{TM}}$ PicoGreen ${ }^{\circledR}$ dsDNA reagent is an ultrasensitive fluorescent nucleic acid stain for quantitating double-stranded DNA (dsDNA) in solution. The fluorescence of the samples was measured using a fluorescence microplate reader (Synergie HT, Bio-Tek, USA) at an excitation of $485 \mathrm{~nm}$ and emission of $528 \mathrm{~nm}$. A five-point standard curve ranging from 0 to $2 \mu \mathrm{g} / \mathrm{ml}$ was also created to allow the determination of the DNA concentration of the samples. Appropriated blanks were used to each group of samples (apatite-coated PCL nanofiber meshes, untreated PCL nanofiber meshes and TCPS). Triplicates were made for each sample or standard used in the experiments. Statistically significant results from PCL nanofiber 
meshes coated with a BCP layer and untreated PCL nanofiber meshes were observed in MTS and DNA quantification assays with the probability level set at $P<0.05$.

\section{RESULTS}

\section{Surface characterization of PCL nanofiber meshes}

The contact-angle results with ultra-pure water at different periods of time for the untreated and $\mathrm{NaOH}$-treated PCL nanofiber meshes are shown in Fig. 1. There was no significant variation observed in the contact angle for the untreated PCL nanofiber meshes. However, for $\mathrm{NaOH}$-treated specimens we observed a significant reduction in the contact angle, which reached zero after only a few seconds. Those results have shown how efficient the $\mathrm{NaOH}$ treatment is in promoting the decrease in the interfacial tension between the liquid and the sample's surface. This is an important attribute to be considered during the $\mathrm{CaP}$ treatment, when electrostatic interactions and ion-exchange reactions take place.

XPS analysis detected small amounts of sodium, probably present as sodium carboxylate, on the NaOH-treated PCL nanofiber meshes (Fig. 2). The same result was observed by Oyane et al. [30], where it was shown that the number of carboxylate residues at the surface of the polymer increased with the concentrations of the $\mathrm{NaOH}$ solutions.

The presence of calcium and phosphorus at the surface of the CaP-treated specimens was also detected (Fig. 2). This result could be related to the early formation of a calcium phosphate phase. Despite being identified by XPS, it was not possible to detect calcium phosphate by infrared (Fig. 4) and TF-XRD analysis (data not shown) immediately after $\mathrm{CaP}$ treatment. This could be due to the presence of

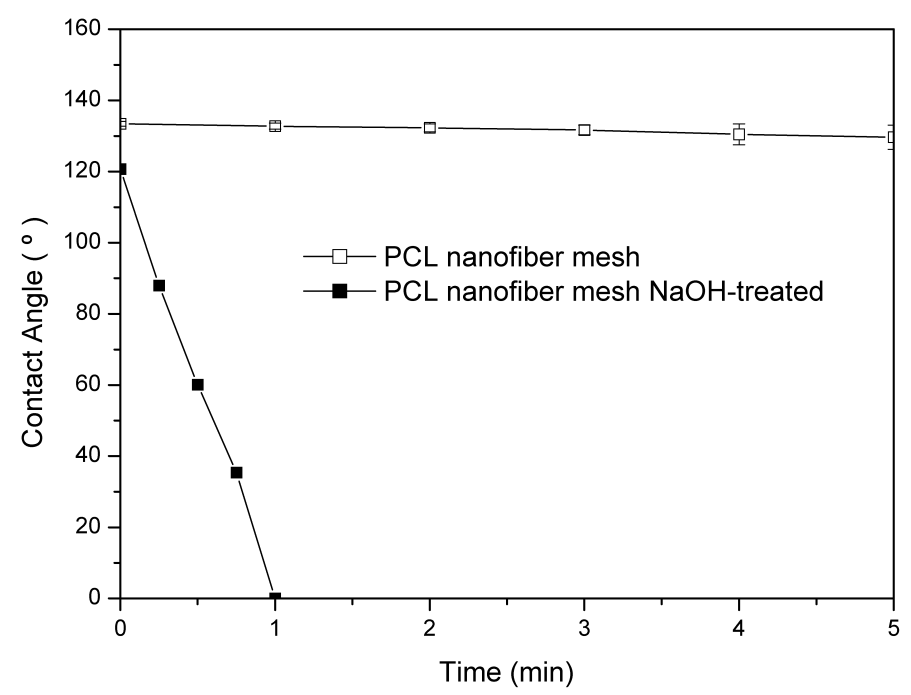

Figure 1. Contact-angle measurements of untreated and $\mathrm{NaOH}$-treated PCL nanofiber meshes. 


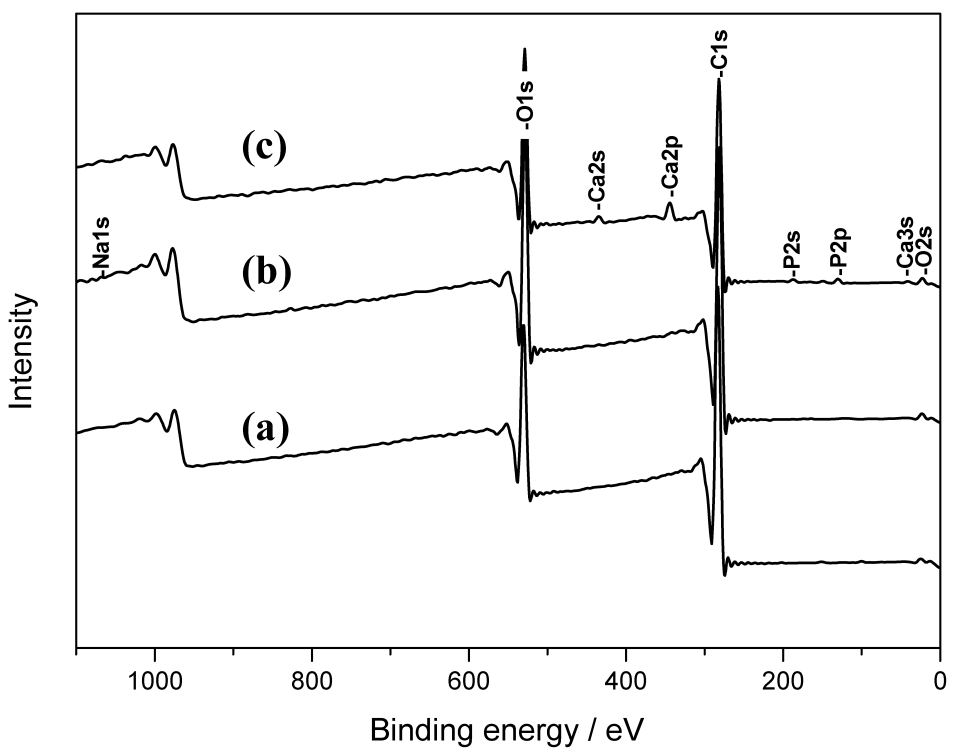

Figure 2. XPS spectra of the surfaces of the untreated PCL nanofiber meshes (a) and those subjected to $\mathrm{NaOH}$ treatment (b) and to $\mathrm{CaP}$ treatment (c).

the calcium phosphate as an amorphous phase not detectable by these techniques. In fact, it has been reported that the infrared spectra of amorphous calcium phosphate (ACP) do not show phosphate absorption bands, and, as it would be expected, it is amorphous according to X-ray diffraction experiments [40]. Therefore, the absence of calcium phosphate features in the TF-XRD and in the infrared spectra can also be attributed to trace amounts of the calcium phosphate at the polymer surface [30].

After immersion in $1.5 \times \mathrm{SBF}$ for $6 \mathrm{~h}$, it was possible to detect the presence of $\mathrm{BCP}$ on the CaP-treated specimens by TF-XRD analysis (Fig. 3). Although the calcium phosphate layer formed in the first hours of immersion in $1.5 \times \mathrm{SBF}$ was predominantly amorphous, an increase in its crystallinity was observed as the immersion time also increased.

The results of the FT-IR-ATR characterization (Fig. 4) show that the BCPcontaining PCL nanofiber meshes present the typical structural bands of PCL and bands found in the mineral phase. The bands at 1727 and $1170 \mathrm{~cm}^{-1}$ can be attributed to the $\mathrm{C}=\mathrm{O}$ and $\mathrm{C}-\mathrm{O}$ absorption bands of PCL, respectively [41, 42]. The contribution of the BCP is observed in the broad band at 1092-962 $\mathrm{cm}^{-1}$, the absorption bands at 603 and $563 \mathrm{~cm}^{-1}$, corresponding to $\mathrm{PO}_{4}^{3-}$ groups [43, 44], and in the bands at 1415 and $875 \mathrm{~cm}^{-1}$, attributed to $\mathrm{CO}_{3}^{2-}$ groups [39, 44]. The presence of carbonate groups suggests the substitution of some phosphate groups, which could be a result of the formation of a carbonated calcium phosphate similar to the inorganic phase of bone, i.e., a bone-like apatite [45].

Figure 5 presents the morphological analysis by SEM of the samples immersed in $1.5 \times \mathrm{SBF}$. It was possible to observe that a BCP layer was formed at the surface 


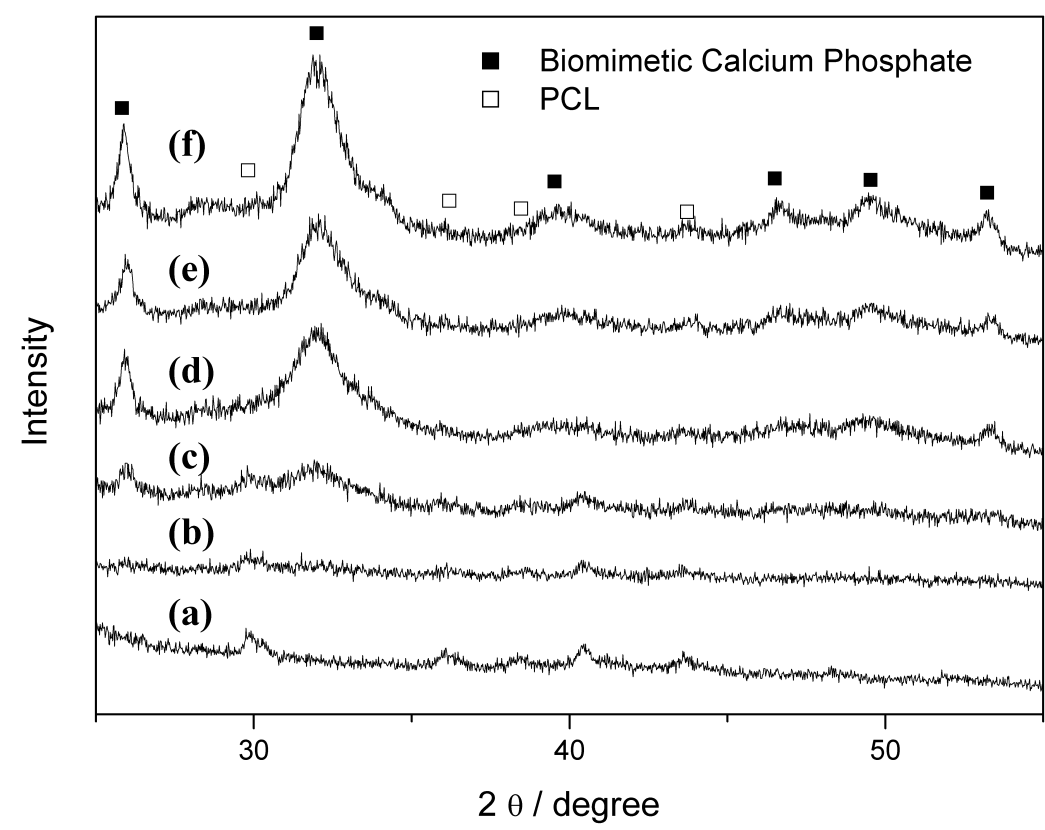

Figure 3. TF-XRD patterns of $\mathrm{NaOH}$-treated (a) and CaP-treated PCL fiber meshes after immersion

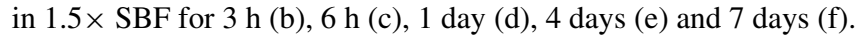

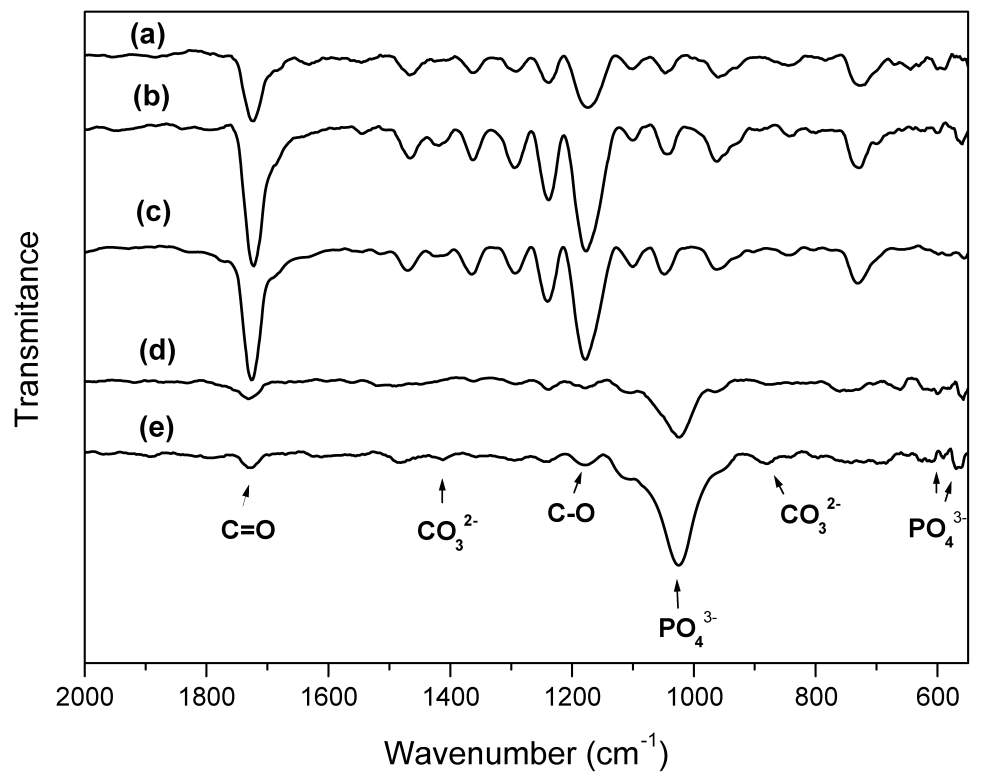

Figure 4. FT-IR-ATR spectra of PCL nanofiber meshes without treatment (a), NaOH-treated (b), CaP-treated (c) and CaP-treated after immersion in $1.5 \times \mathrm{SBF}$ for 2 days (d) and 4 days (e). 

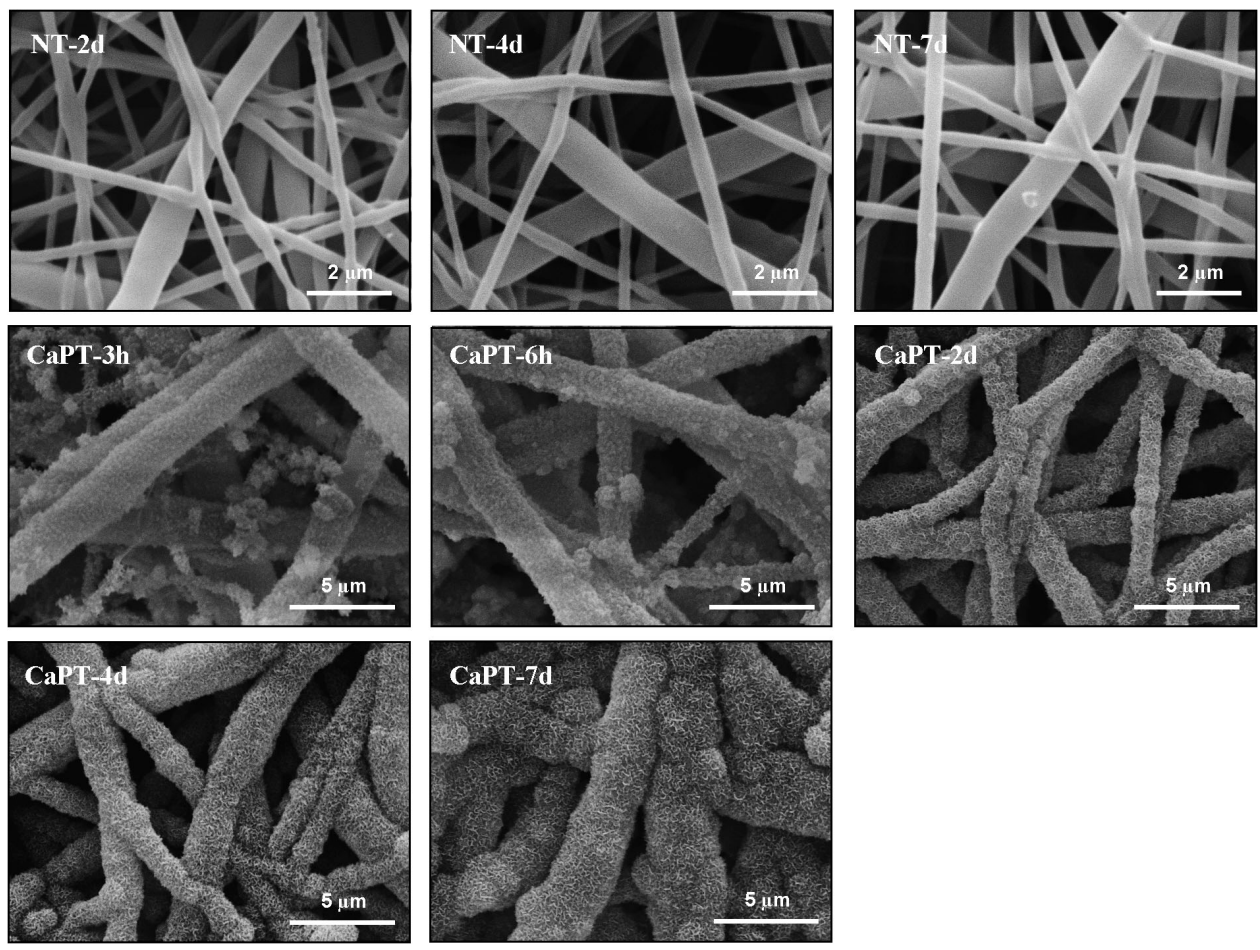

Figure 5. SEM micrographs illustrating $\mathrm{NaOH}$-treated (NT) and CaP-treated (CaPT) PCL nanofiber meshes after immersion in $1.5 \times$ SBF for $3 \mathrm{~h}$ (CaPT-3h), $6 \mathrm{~h}$ (CaPT- $6 \mathrm{~h}), 2$ days (NT-2d and CaPT-2d), 4 days (NT-4d and CaPT-4d) and 7 days (NT-7d and CaPT-7d).

of the CaP-treated specimens in the first hours of immersion. Furthermore, this BCP layer was dense and deposited uniformly at the surface of the nanofibers, keeping their morphology and, which is the most important, it did not promote the obstruction of the pores. On the other hand, nanofiber meshes that were only subjected to the $\mathrm{NaOH}$ treatement, were not able to induce the formation of a $\mathrm{BCP}$ even after 7 days of immersion in $1.5 \times \mathrm{SBF}$.

Although the calcium phosphate phase on the CaP-treated specimens immersed in $1.5 \times \mathrm{SBF}$ could not be detected by TF-XRD before $6 \mathrm{~h}$ of incubation (Fig. 3), the presence of calcium and phosphorus elements could be already detected by EDS after $3 \mathrm{~h}$ of incubation (Fig. 6). EDS spectra also revealed the presence of carbon and oxygen peaks. As the immersion time in $1.5 \times \mathrm{SBF}$ increased, the intensity of the peaks attributed to calcium and phosphorus elements was also increased, while the relative intensity of the carbon and oxygen peaks decreased. Those results suggest that the carbon and the oxygen detected belong mainly to the polymer phase, which becomes less 'detectable' with increasing thickness of the BCP layer. In fact, in Fig. 5 it can be seen that the thickness of the BCP layer increased with the time of immersion in $1.5 \times \mathrm{SBF}$. Similar results were obtained in other works on biomimetic calcium phosphate coatings of polymers $[12,46]$. 

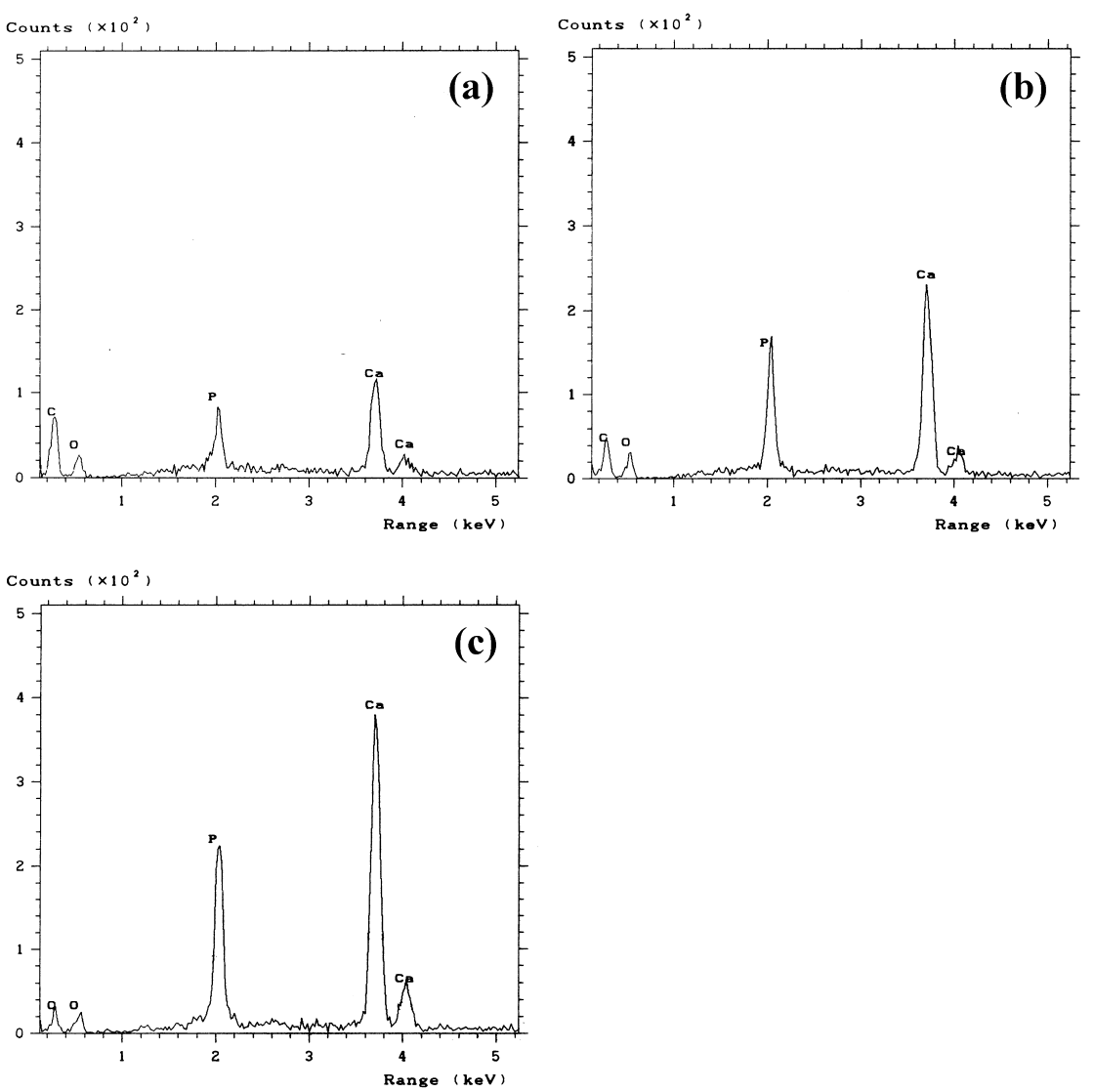

Figure 6. EDS spectra of CaP-treated PCL nanofiber meshes after immersion in $1.5 \times \mathrm{SBF}$ for $3 \mathrm{~h}(\mathrm{a})$, $6 \mathrm{~h}$ (b) and 1 day (c).

Osteoblast response to PCL nanofiber meshes coated with a biomimetic calcium phosphate layer

Considering the morphological analysis, Saos-2 cells attached and proliferated on all substrates tested after only 3 days in culture. However, some significant differences in cell morphology were observed. A typical cube-shaped, epitheliallike morphology of cells was observed on the untreated PCL nanofiber meshes and TCPS materials (Fig. 7). Cells on these substrates had a round cellular body and extended filipodia and microextensions, maintaining physical contact with the substratum and the neighbor cells. In contrast, osteoblasts on PCL nanofiber meshes coated with a BCP layer presented an elongated and flattened morphology. Furthermore, the number of cells was kept at comparable levels between 7 and 14 days for osteoblast-like cells cultured on control materials. Conversely, on coated samples, an increment of the cell number was observed, with almost all the nanofiber mesh surface colonized. In both untreated and coated PCL nanofiber 

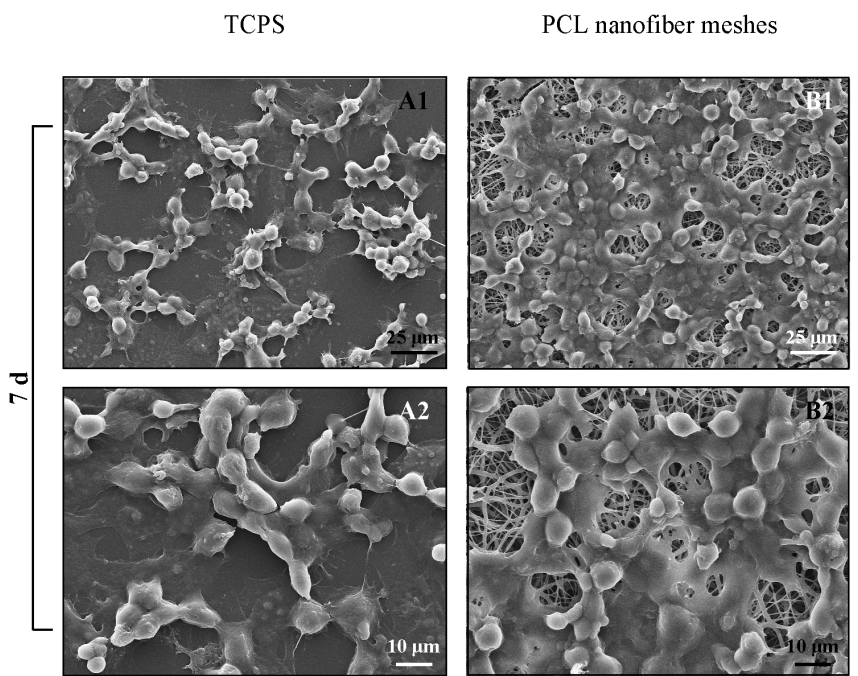
PCL nanofiber meshes coated with
a BCP layer
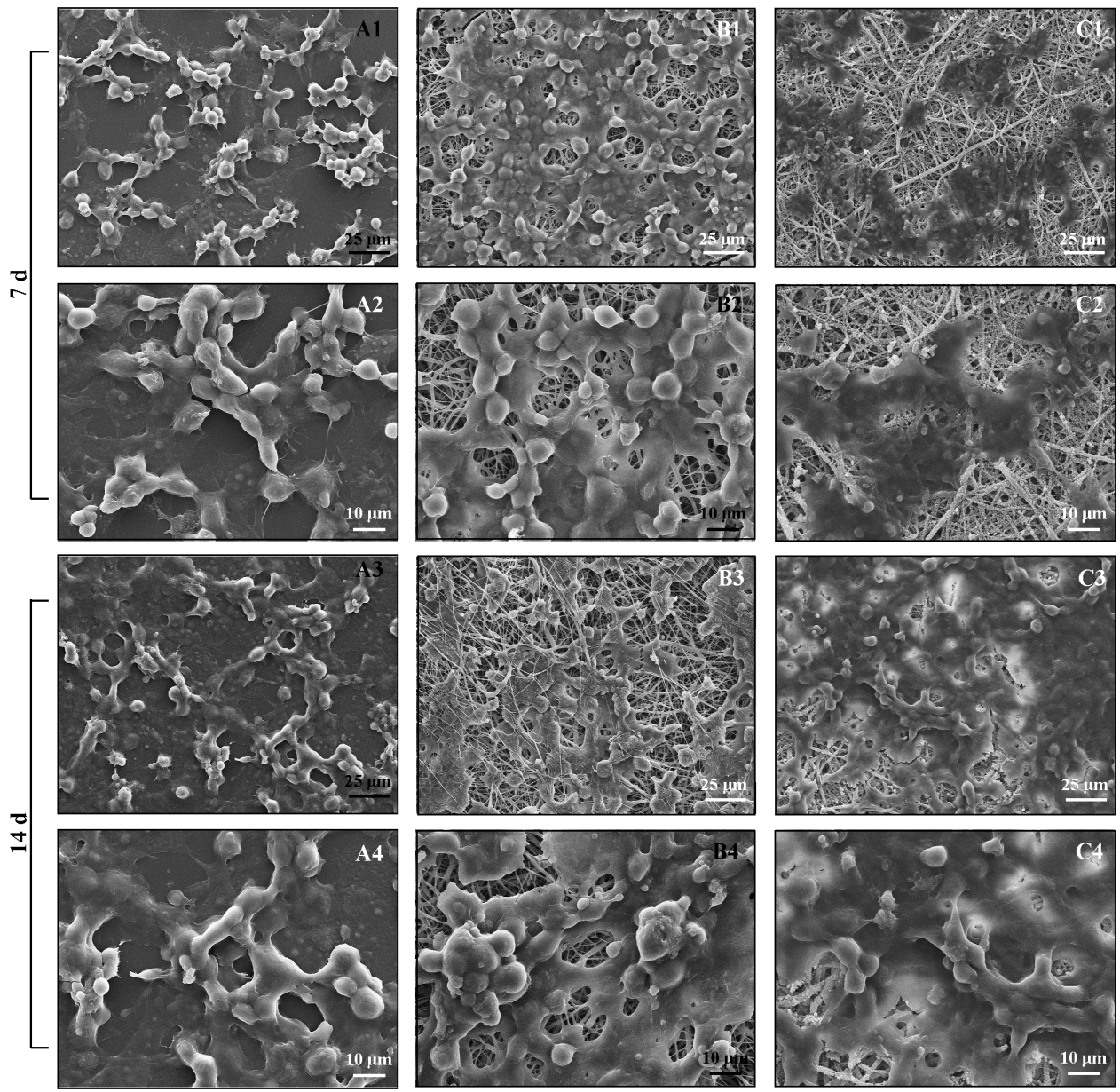

Figure 7. Morphology of Saos-2 cells cultured for 7 and 14 days on TCPS (A), untreated PCL nanofiber meshes (B) and PCL nanofiber meshes coated with a biomimetic calcium phosphate layer (C).

meshes it was possible to visualize more than one monolayer of cells, with cytoplasms of different cells merging together.

The cell viability assay (MTS test) demonstrated that the cells remained viable during the experiment, with consistently increase of the metabolic activity (Fig. 8). The highest viability values were observed for longer (14 days) culture periods on PCL nanofiber meshes coated with BCP. Earlier time points (1, 3 and 7 days) evidenced that the osteoblast-like cells cultured on untreated PCL nanofiber meshes present higher values of metabolic activities. Longer culture times tend to cause cells to become fully confluent in a monolayer, resulting in a decrease of cell viability. 


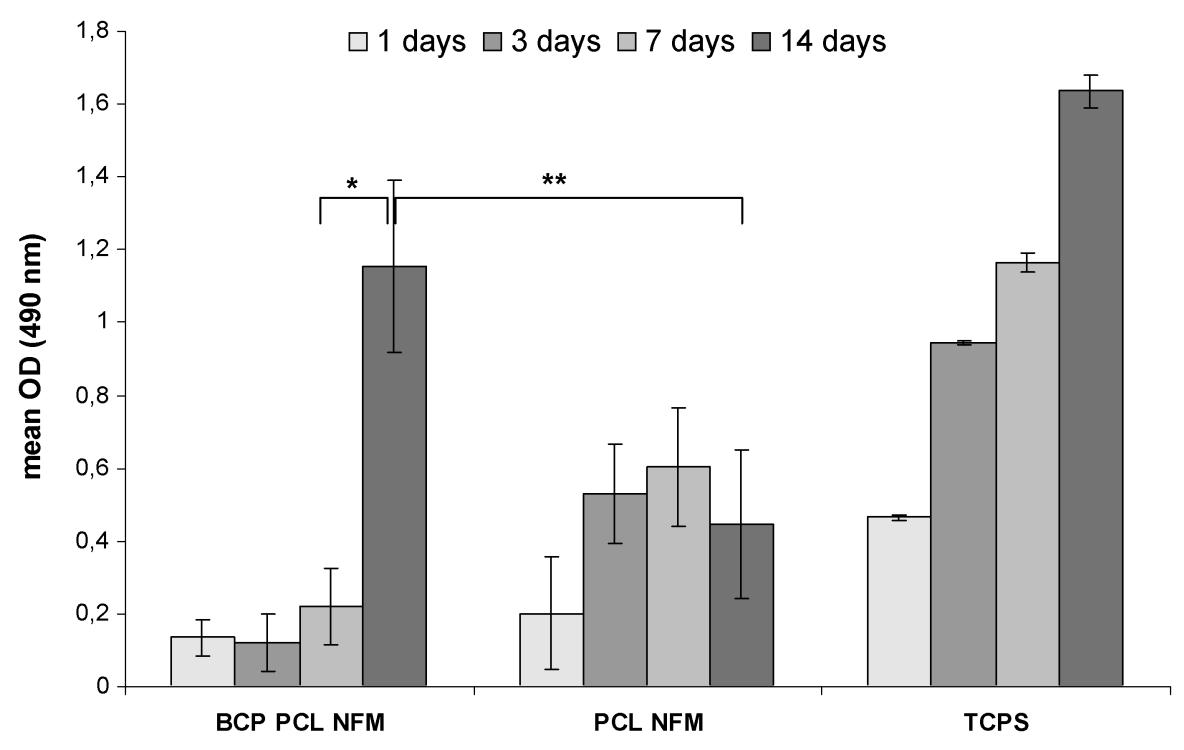

Figure 8. Cell viability of human osteoblast-like cells grown on PCL nanofiber meshes coated with a biomimetic calcium phosphate layer (BCP PCL NFM) and untreated PCL nanofiber meshes (PCL NFM). TCPS, tissue-culture polystyrene coverslips. ${ }^{*} P=5.76 \times 10^{-10}, * * P=7.85 \times 10^{-8}$.

The DNA content of the osteoblast-nanofiber mesh constructs was measured to quantify the osteoblast expansion and proliferation on the untreated and biomimetically calcium phosphate coated PCL nanofiber meshes. A remarkable increment of DNA content was observed for coated PCL nanofiber meshes, reaching values similar to those observed for tissue culture polystyrene after 14 days (Fig. 9). The lowest proliferation rate was observed in untreated PCL nanofiber meshes. The results of morphological analysis were confirmed by the cell viability and proliferation.

\section{DISCUSSION}

Electrospinning has been proposed as a promising technique to produce scaffolds consisting of non-woven fiber meshes with fiber diameters ranging from a few micrometers down to the nanometer range. These structures have dimensions and morphology resembling the extracellular matrix of human tissues. It is believed that these structures provide the conditions necessary to support cell attachment, proliferation and differentiation. It has been demonstrated that the highly interconnected porous structure of the electrospun nanofibers together with a high surface area allow an efficient transport of ions [39]. This is of extreme importance for the good cell response to the structures supporting cell engraftment. Moreover, it is relevant to produce coatings on polymer nanofibers without compromising their original structure and morphology.

As was shown in Fig. 1, there was an accentuated decrease of the contact angle values of samples subjected to the $\mathrm{NaOH}$ treatment. The increasing wettability of 


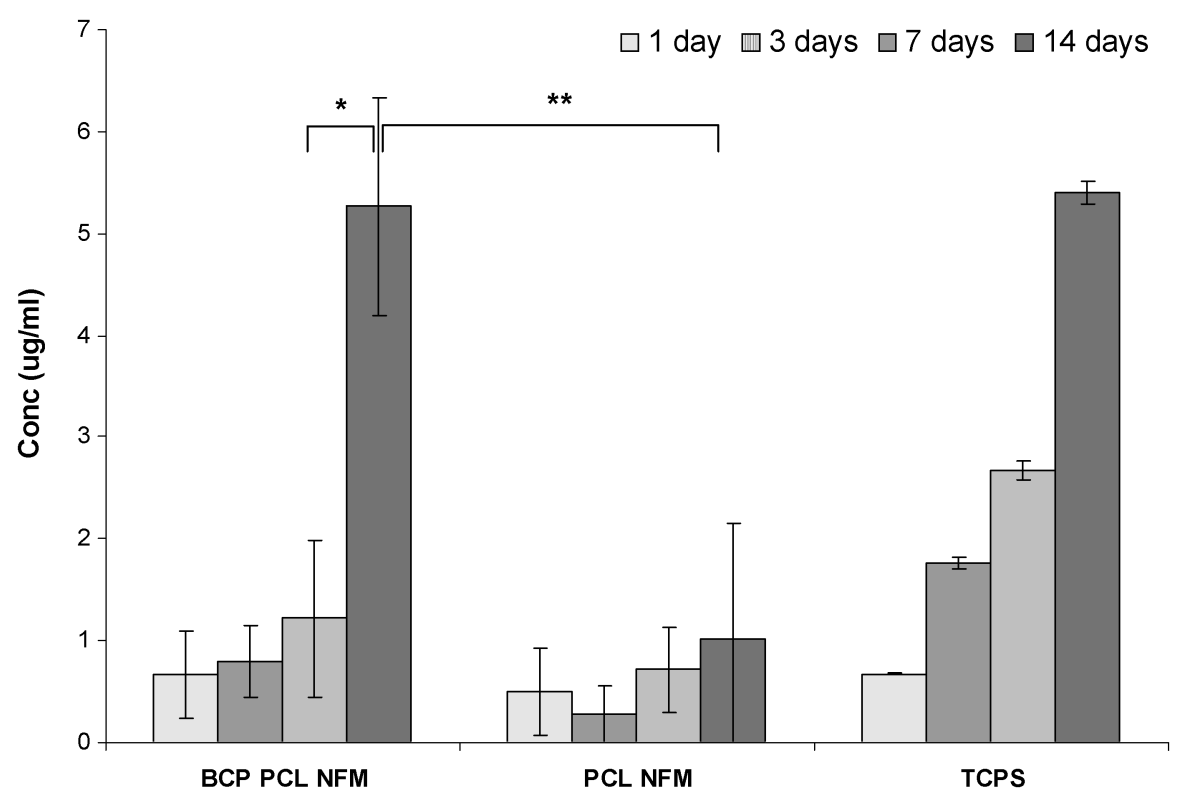

Figure 9. DNA content of human osteoblast-like cells grown on PCL nanofiber meshes coated with a biomimetic calcium phosphate layer (BCP PCL NFM) and untreated PCL nanofiber meshes (PCL NFM). TCPS, tissue-culture polystyrene coverslips. $* P=1.95 \times 10^{-10}, * * P=4.04 \times 10^{-8}$.

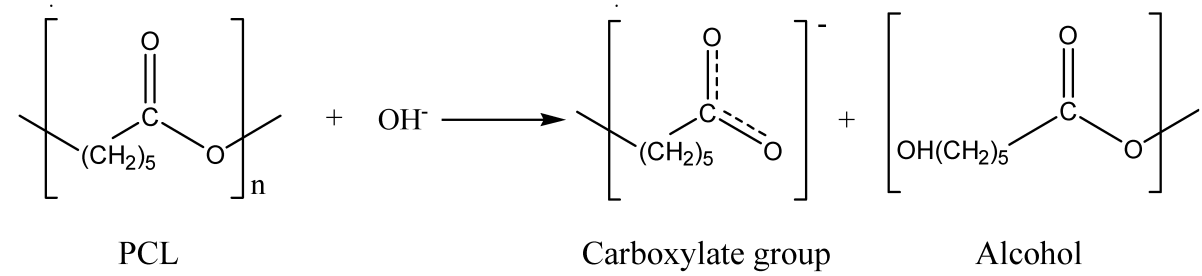

Figure 10. Hydrolysis of PCL after $\mathrm{NaOH}$ treatment.

the PCL nanofiber meshes could be related to a partial hydrolysis of the polyester by the strongly nucleophilic reagent, i.e., the hydroxide ion. This treatment may lead to the cleavage of the ester linkages producing hydrophilic terminal groups, such as carboxylate and hydroxyl groups [47], due to the formation of carboxylate salts and alcohol as products. A probable scheme for this reaction is shown in Fig. 10.

The presence of carboxylate groups on PCL nanofiber meshes was not sufficient to induce BCP coating after immersion in $1.5 \times \mathrm{SBF}$. On the other hand, samples immersed in the calcium and phosphate solutions were shown to have the capacity to induce the formation of a BCP layer after immersion in $1.5 \times \mathrm{SBF}$ for several time periods, as observed by SEM (Fig. 5). Moreover, the formation of the BCP layer did not obstructed the pores of the nanofiber meshes. The BCP layer thickness increased directly with the immersion time by consuming calcium and phosphate ions from the solution. The thickness of the layer can be controlled by adjusting 
the time of immersion of the specimens in $1.5 \times \mathrm{SBF}$. The formation of the BCP coating at the surface of the nanofiber meshes CaP-treated can be explained in three steps: (i) when the $\mathrm{NaOH}$-treated specimens are placed into the calcium chloride solution, calcium ions can be attracted to the polymer surfaces by either an electrostatic interaction and an ion-exchange between the sodium linked to the carboxylate groups [30,48]; (ii) after immersion in the phosphate solution, those calcium ions will interact with the phosphate ions to promote the formation of a calcium phosphate at the polymer surface, (iii) when immersed in $1.5 \times \mathrm{SBF}$, the calcium phosphate formed on the polymer surface will act as a seed layer for the $\mathrm{BCP}$ to grow by consuming the calcium and phosphate ions from the solution.

Since the carboxylate groups are believed to induce BCP nucleation when immersed in SBF solution [25], it was expected that with only $\mathrm{NaOH}$ treatment it would be possible to induce the formation of BCP. However, no BCP deposition was observed even after 7 days of immersion in $1.5 \times \mathrm{SBF}$; this suggests that it is necessary a period of incubation longer to induce the nucleation of the BCP. Chen et al. [39] demonstrated that the incorporation of carboxylate groups in a PLLA surface requires an immersion time in SBF longer than 2 weeks for the nucleation of BCP.

As it was shown in Fig. 5, after immersion in $1.5 \times$ SBF for 7 days, the BCP layer formed at the surface of CaP-treated PCL nanofiber meshes became more dense and compact and started to obstruct the initial pores. Due to this, and in order to perform the biological assays, it was chosen the samples that were immersed in $1.5 \times \mathrm{SBF}$ for 4 days, since they had a more uniform coating, preserving the initial aspect of the pores and keeping their interconnectivity.

As stated in the results, human osteoblast-like cells were able to grow on both biomimetically calcium-phosphate-coated and untreated PCL nanofibers. Therefore, the cells tended to undergo cytoskeletal reorganization only when cultured in the presence of the BCP. Shah et al. [49] hypothesized that when osteoblasts are unable to adapt to a material surface they enhance many cell processes, in order to produce sufficient anchorage proteins for attachment. In addition, they demonstrated that cells with long cellular extensions also showed a larger cell size and a lower attachment than cells with a compact cell shape. A similar behavior was observed in this work (Fig. 7). The comparison of the morphological alterations and cytoskeletal restructuring of osteoblast-like cells cultured on materials containing a BCP coating and on uncoated samples was also performed by other authors $[9,14,50,51]$. Furthermore, the crystallinity of the BCP may determine specific cell response like the organization of cytoskeleton filaments and cell proliferation mechanisms [52]. Reported results indicate that the proliferation of osteoblasts is slower for more amorphous surfaces, mainly due to the development of less organized cytoskeleton. The $\mathrm{BCP}$ formed on CaP-treated specimens incubated in $1.5 \times$ SBF for 7 days presented a superior crystallinity. However, as mentioned, the accentuated variations of the morphology, when compared to the other CaP-treated 
samples incubated for shorter time periods, hindered their use in the biological assays.

The lower viability at short-cultured periods of the cells seeded on nanofiber meshes coated with BCP, when compared to the cells seeded on untreated PCL nanofibers, may be related to the calcium and phosphate ionic concentrations in the cell microenvironment at early time points. The presence of these ions could have a deleterious effect over cellular proliferation, as it was recently reported [53]. However, at longer culture periods ( 2 weeks), an enhanced osteoblast proliferation was observed for the structures coated with the BCP, when compared to untreated PCL nanofiber meshes. Similar results were also reported by Ciapetti et al. [3]. These authors reported the enhancement of the osteoblasts colonization on PCL scaffolds reinforced with hydroxyapatite (HA) when compared to PCL scaffolds for long-term culture periods. A large percentage of dead cells was also observed until 7 days of culture of preosteoblastic cells (MC3T3-E1 cell line) on precursor apatite spheres, whereas after 14 days the remaining viable cells were able to proliferate [54]. In the case of the coated nanofiber meshes, the increase in the cell proliferation after two weeks of culture may be related to interactions of the BCP coating with some substances present in the medium, leading to the formation of a more suitable microenvironment for the cells. Indeed, it was reported previously that the calcium phosphate layer can adsorb proteins from the culture medium that may enhance cell proliferation and in general cell activity [55].

Previous studies [56, 57] had also evaluated the osteoblast attachment and proliferation on composites of PCL nanofibers containing nanoparticles of calcium carbonate $\left(\mathrm{CaCO}_{3}\right)$ or HA. It was shown that the viability of the cells decreases as the amount of $\mathrm{CaCO}_{3}$ in the composite increases [56]. In addition, cells seeded on PCL/HA fibrous scaffolds presented higher viability than the cells seeded on scaffolds containing PCL/CaCO 3 or PCL alone [57]. That behavior was attributed to the ability of HA to promote bone-cell activities.

The procedure used in this work has proven to be effective in coating electrospun nanofiber meshes with BCP without compromising the initial morphology. This procedure has several advantages when compared to other approaches, including the fact that the coating process is compatible with physiological conditions. Moreover, it promotes a homogeneous coating of the polymer surfaces with a mineral phase with chemical composition similar to that found in bone. The positive aspects of the coated structures were confirmed by the biological studies that showed increased cell activities at longer time points when compared with untreated PCL samples.

\section{CONCLUSIONS}

The coating conditions were effective to induce the formation of a $\mathrm{BCP}$ layer on PCL nanofiber meshes without damage their structures. The PCL nanofiber meshes coated with BCP were more effective for supporting cell attachment and proliferation when compared to untreated meshes for longer periods of time. The 
results point out that PCL nanofiber meshes coated with BCP can be considered for bone-tissue engineering applications. This work is one of the first reports on the coating of PCL nanofiber meshes with BCP layers.

Studies are already conducted to address the effect of the BCP formation at the surface of PCL nanofiber meshes on osteogenic differentiation of human bonemarrow-derived stromal cells (hBMSCs).

\section{Acknowledgements}

This work was partially supported by the EU Integrated Project GENOSTEM (Adult Mesenchymal Stem Cells Engineering for connective tissue disorders: from the bench to the bed side, No. LSH503161) and by the project Naturally Nano (POCI/EME/58982/2004), financed by the Portuguese Foundation for Science and Technology (FCT). A. M. would like to thank FCT for his PhD grant (SFRH/BD/24382/2005). I. B. L. also thanks FCT for a PhD scholarship (SFRH/BD/9031/2002). This work was carried out under the scope of the European NoE EXPERTISSUES (NMP3-CT-2004-500283).

\section{REFERENCES}

1. F. E. Wiria, K. F. Leong, C. K. Chua and Y. Liu, Acta Biomater. 3, 1 (2007).

2. F. Causa, P. A. Netti, L. Ambrosio, G. Ciapetti, N. Baldini, S. Pagani, D. Martini and A. Giunti, J. Biomed. Mater. Res. Part A 76, 151 (2006).

3. G. Ciapetti, L. Ambrosio, L. Savarino, D. Granchi, E. Cenni, N. Baldini, S. Pagani, S. Guizzardi, F. Causa and A. Giunti, Biomaterials 24, 3815 (2003).

4. A. G. A. Coombes, S. C. Rizzi, M. Williamson, J. E. Barralet, S. Downes and W. A. Wallace, Biomaterials 25, 315 (2004).

5. A. J. Salgado, O. P. Coutinho and R. L. Reis, Macromol. Biosci. 4, 743 (2004).

6. Y. Shikinami and M. Okuno, Biomaterials 20, 859 (1999).

7. R. Zhang and P. X. Ma, J. Biomed. Mater. Res. 45, 285 (1999).

8. I. B. Leonor, R. A. Sousa, A. M. Cunha, R. L. Reis, Z. P. Zhong and D. Greenspan, J. Mater. Sci. Mater. Med. 13, 939 (2002).

9. A. J. Salgado, J. E. Figueiredo, O. P. Coutinho and R. L. Reis, J. Mater. Sci. Mater. Med. 16, 267 (2005).

10. I. B. Leonor, H.-M. Kim, F. Balas, M. Kawashita, R. L. Reis, T. Kokubo and T. Nakamura, J. Tissue Eng. Regul. Med. 18, 1923 (2007).

11. P. J. Ter Brugge, J. G. Wolke and J. A. Jansen, J. Biomed. Mater. Res. 60, 70 (2002).

12. A. L. Oliveira, C. M. Alves and R. L. Reis, J. Mater. Sci. Mater. Med. 13, 1181 (2002).

13. J. E. Hulshoff, K. van Dijk, J. E. De Ruijter, F. J. Rietveld, L. A. Ginsel and J. A. Jansen, J. Biomed. Mater. Res. 40, 464 (1998).

14. J. L. Ong, D. R. Villarreal, R. Cavin and K. Ma, J. Mater. Sci. Mater. Med. 12, 491 (2001).

15. A. L. Oliveira, P. B. Malafaya and R. L. Reis, Biomaterials 24, 2575 (2003).

16. I. B. Leonor, H. M. Kim, F. Balas, M. Kawashita, R. L. Reis, T. Kokubo and T. Nakamura, Bioceramics 17, 453 (2005).

17. T. Taguchi, Y. Muraoka, H. Matsuyama, A. Kishida and M. Akashi, Biomaterials 22, 53 (2001).

18. E. N. Antonov, V. N. Bagratashvili, L. I. Krotova and V. K. Popov, Bioceramics 13, 63 (2000).

19. Y. Abe, T. Kokubo and T. Yamamuro, J. Mater. Sci. Mater. Med. 1, 233 (1990). 
20. R. L. Reis, A. M. Cunha, M. H. Fernandes and R. N. Correia, J. Mater. Sci. Mater. Med. 8, 897 (1997).

21. K. Hata, T. Kokubo, T. Nakamura and T. Yamamuro, J. Am. Ceram. Soc. 78, 1049 (1995).

22. T. Kokubo, Biomaterials 12, 155 (1991).

23. T. Kokubo, H. Kushitani, S. Sakka, T. Kitsugi and T. Yamamuro, J. Biomed. Mater. Res. 24, 721 (1990).

24. A. Oyane, M. Minoda, T. Miyamoto, R. Takahashi, K. Nakanishi, H. M. Kim, T. Kokubo and T. Nakamura, J. Biomed. Mater. Res. 47, 367 (1999).

25. M. Tanahashi and T. Matsuda, J. Biomed. Mater. Res. 34, 305 (1997).

26. T. Kokubo, H. M. Kim, M. Kawashita and T. Nakamura, Z. Kardiol. 90 (Suppl. 3), 86 (2001).

27. A. Oyane, M. Kawashita, T. Kokubo, M. Minoda, T. Miyamoto and T. Nakamura, J. Ceram. Soc. Jpn 110, 248 (2002).

28. W. L. Murphy and D. J. Mooney, J. Am. Chem. Soc. 124, 1910 (2002).

29. M. Kawashita, M. Nakao, M. Minoda, H. M. Kim, T. Beppu, T. Miyamoto, T. Kokubo and T. Nakamura, Biomaterials 24, 2477 (2003).

30. A. Oyane, M. Uchida, C. Choong, J. Triffitt, J. Jones and A. Ito, Biomaterials 26, 2407 (2005).

31. Z.-M. Huang, Y. Z. Zhang, M. Kotaki and S. Ramakrishna, Comp. Sci. Tech. 63, 2223 (2003).

32. X. Geng, O. H. Kwon and J. Jang, Biomaterials 26, 5427 (2005).

33. T. G. Kim and T. G. Park, Tissue Eng. 12, 221 (2006).

34. L. A. Smith and P. X. Ma, Colloids Surfaces B: Biointerfaces 39, 125 (2004).

35. S. Ramakrishna, K. Fujihara, W. E. Teo, T. Yong, Z. W. Ma and R. Ramaseshan, Mater. Today 9, 40 (2006).

36. Q. P. Pham, U. Sharma and A. G. Mikos, Biomacromolecules 7, 2796 (2006).

37. W. J. Li, C. T. Laurencin, E. J. Caterson, R. S. Tuan and F. K. Ko, J. Biomed. Mater. Res. 60, 613 (2002).

38. W. J. Li, R. Tuli, X. Huang, P. Laquerriere and R. S. Tuan, Biomaterials 26, 5158 (2005).

39. J. L. Chen, B. Chu and B. S. Hsiao, J. Biomed. Mater. Res. Part A 79, 307 (2006).

40. S. V. Dorozhkin and M. Epple, Angew. Chem. Int. Edn Engl. 41, 3130 (2002).

41. T. Elzein, M. Nasser-Eddine, C. Delaite, S. Bistac and P. Dumas, J. Colloid Interface Sci. 273, 381 (2004).

42. H. W. Kim, J. C. Knowles and H. E. Kim, J. Biomed. Mater. Res. Part B 70, 240 (2004).

43. D. W. Choi, K. G. Marra and P. N. Kumta, Mater. Res. Bull. 39, 417 (2004).

44. P. Taddei, A. Tinti, M. Reggiani and C. Fagnano, J. Mol. Struct. 744, 135 (2005).

45. S. Mann, Biomineralization: Principles and Concepts in Bioinorganic Materials Chemistry. Oxford University Press, Oxford (2001).

46. A. L. Oliveira, C. Elvira, R. L. Reis, B. Vazquez and J. San Roman, J. Mater. Sci. Mater. Med. 10, 827 (1999).

47. J. Pena, T. Corrales, I. Izquierdo-Barba, M. C. Serrano, M. T. Portoles, R. Pagani and M. ValletRegi, J. Biomed. Mater. Res. A 76, 788 (2006).

48. A. Oyane, M. Uchida, Y. Yokoyama, C. Choong, J. Triffitt and A. Ito, J. Biomed. Mater. Res. Part. A 75, 138 (2005).

49. A. K. Shah, R. K. Sinha, N. J. Hickok and R. S. Tuan, Bone 24, 499 (1999).

50. P. J. Ter Brugge and J. A. Jansen, Biomaterials 23, 3269 (2002).

51. P. A. Ramires, A. Romito, F. Cosentino and E. Milella, Biomaterials 22, 1467 (2001).

52. L. Chou, B. Marek and W. R. Wagner, Biomaterials 20, 977 (1999).

53. C. S. Adams, K. Mansfield, R. L. Perlot and I. M. Shapiro, J. Biol. Chem. 276, 20316 (2001).

54. Y. F. Chou, W. Huang, J. C. Dunn, T. A. Miller and B. M. Wu, Biomaterials 26, 285 (2005).

55. A. El-Ghannam, P. Ducheyne and I. M. Shapiro, Biomaterials 18, 295 (1997).

56. K. Fujihara, M. Kotaki and S. Ramakrishna, Biomaterials 26, 4139 (2005).

57. P. Wutticharoenmongkol, N. Sanchavanakit, P. Pavasant and P. Supaphol, Macromol. Biosci. 6, 70 (2006). 